\title{
REALISMO E FOTOGRAFIA: DIORAMAS DE HIROSHI SUGIMOTO DO MUSEU DE HISTÓRIA NATURAL DE NOVA IORQUE
}

\author{
Angela Prada de Almeida ${ }^{\text {** }}$ \\ Universidade de Brasília
}

\section{RESUMO:}

Este texto tem como objetivo analisar a representação dos Dioramas nos Museus de História Natural, tendo como ponto de partida o olhar do fotógrafo japonês Hiroshi Sugimoto. Sugimoto fotografou estes cenários artificiais, colocando em questão o discurso do realismo da imagem fotográfica. O olhar do fotógrafo envolve estruturas de cognição. A visão monocular e a representação do espaço em perspectiva implicam na tradição de conceber o que é visto como "realidade". Paradigmas do discurso fotográfico e características próprias da fotografia inter-relacionam-se com particularidades da cultura japonesa. As fotografias e ideias imagéticas criadas por Sugimoto sugerem conceitos teóricos e suscitam análises sobre construções culturais: maneiras de conceber a visualidade que nos cerca, a partir do olhar do fotógrafo.

\section{PALAVRAS-CHAVE:}

Hiroshi Sugimoto, Diorama, Fotografia, Perspectiva, Realismo.

\section{Realism and Photography: Dioramas by Hiroshi Sugimoto.}

\begin{abstract}
:
This text aims to analyze the representation of the Dioramas, from the viewpoint of Japanese photographer Hiroshi Sugimoto. Sugimoto photographed these artificial scenarios, questioning the realism discourse of the photographic image. The eye of the photographer involves structures of knowledge. The monocular vision and perspective representation implies in the tradition of conceiving what is seen as "reality". Paradigms of photographic discourse and characteristics of photography inter-relate to the particularities of Japanese culture. The photographs and concepts stated by Sugimoto suggest theoretical debates and raise photographic analysis of cultural constructions: ways of conceiving the visual world that surrounds us, through the gaze of the photographer.
\end{abstract}

\section{KEY-WORDS:}

Hiroshi Sugimoto, Diorama, Photography, Perspective, Realism.

\footnotetext{
I * Doutora em Multimeios pela Universidade Estadual de Campinas (Unicamp). Mestre em Artes Visuais pela Universidade Federal do Rio de Janeiro (UFRJ). Especialista em Jornalismo Cultural pela Pontifícia Universidade Católica de São Paulo (PUC/SP). Professora adjunta de fotografia do curso de Artes Plásticas do Instituto de Artes da Universidade de Brasília (UNB). Fotografias publicadas em diversos veículos:The New York Times, Folha de SP, entre outros. Realizou diversas exposições e tem vários textos publicados na área de fotografia.
} 
Hiroshi Sugimoto, artista japonês contemporâneo, parece tomar ao pé da letra a afirmação de Dubois (1993, p. I5) sobre ser impossível pensar a fotografia deslocada de seu ato fundante, daquele que a faz ser. Combinando influências da arte conceitual e da cultura japonesa, a arte do fotógrafo japonês se concentra nos pilares básicos da constituição do ato fotográfico. Sugimoto interpreta e, ao mesmo tempo, subverte os clássicos paradigmas do discurso fotográfico em imagens que desafiam observadores astutos a inquirir sobre a natureza da fotografia e sobre as múltiplas implicações teóricas que esse discurso carrega.

Dividido entre um forte espírito tradicionalista japonês e reflexões contemporâneas que interligam obra e discurso, sua trajetória é marcada por influências provenientes dos dois lados do globo. Repartido entre Japão e Estados Unidos, entre antiguidade japonesa e arte contemporânea, contracultura americana e princípios religiosos orientais, o artista recusa rótulos. Resultaria inadequado denominá-lo "artista contemporâneo" ou "fotógrafo japonês".

Articulador visionário, Sugimoto combina, com seu olhar retrospectivo, conceitos contemporâneos e discussões sobre as origens da visão. A própria natureza da escrita da luz ${ }^{2}$ é colocada em questão imageticamente. $O$ que Sugimoto efetivamente discute em seu trabalho são conceitos da fotografia, a essência do fazer fotográfico que se confunde com o ato de observar o que nos circunda. Além das imagens que estimulam discussões sobre a natureza da fotografia, o artista surge como articulador de poderosos conceitos sobre suas obras. As palavras de luz de Sugimoto nos são ofertadas em entrevistas e pequenos trechos escritos. Econômico em suas declarações, as ideias imagéticas proferidas pelo artista sugerem conceitos. Suas fotografias suscitam análises sobre construções culturais fotográficas: nossa maneira de conceber a visualidade que nos cerca, a partir da fotografia.

\section{Dioramas}

Sugimoto se mudou de Tóquio para Nova lorque em 1974 e, logo ao chegar, para conhecer melhor a cidade, fez passeios turísticos. Um lugar que chamou especialmente sua atenção foi o Museu de História Natural. $O$ artista se impressionou com uma das principais atrações do Museu de História Natural de Nova lorque: os Dioramas. Dioramas são cenários especialmente montados, utilizados contemporaneamente em Museus de História Natural, que nos dão a ilusão de realismo. No Museu de História Natural de Nova lorque, os Dioramas são construídos através de efeitos de luz, fundos pintados e animais empalhados. Esses cenários exibem uma espécie de teatro congelado que nos coloca diante de aparições de habitats que impressionam pelo grau de realismo.

Sugimoto se tornou um freqüentador assíduo do museu. Sua motivação para as frequentes visitas foi a configuração dos cenários. Atormentado pela artificialidade dos Dioramas e pelas modificações percebidas ao observá-los com um olho só, o fotógrafo decidiu levar a experiência seriamente: "A natureza da minha visão poderia ser projetada na fotografia, de tal forma que isso pudesse ser a minha arte"3. Sugimoto passou a fotografar os Dioramas com uma câmera formato grande ( $8 \times 10$ polegadas.).A abertura do diafragma

20 químico e artista britânico Sir John Herschel (1792-187I) foi o inventor do termo "fotografia" que significa literalmente:"escrita da luz" em 1839.

3 "The nature of my vision can be projected into photography so I can call it my art." (SUGIMOTO, 2006). 
manteve-se constante: $\mathrm{F} 64$. $O$ indicador " $F$ 64" corresponde à menor abertura de diafragma possível neste tipo de câmera. $O$ resultado são imagens com muita profundidade de campo e detalhes precisos em todos os planos.

Para compensar a abertura diminuta, o tempo de exposição das fotografias tornou-se extremamente longo (em algumas tomadas, cerca de uma hora). Vestido de preto, para evitar o registro de qualquer tipo de reflexo indesejado sobre os vidros de proteção, Sugimoto utilizou durante as tomadas, uma cartolina preta sobre as áreas mais claras, compensando o tempo de exposição dos planos de fundo, para que os detalhes mais luminosos ficassem registrados.

Vejamos alguns exemplos de imagens dos Dioramas do Museu de História Natural de Nova lorque de autoria de Sugimoto:

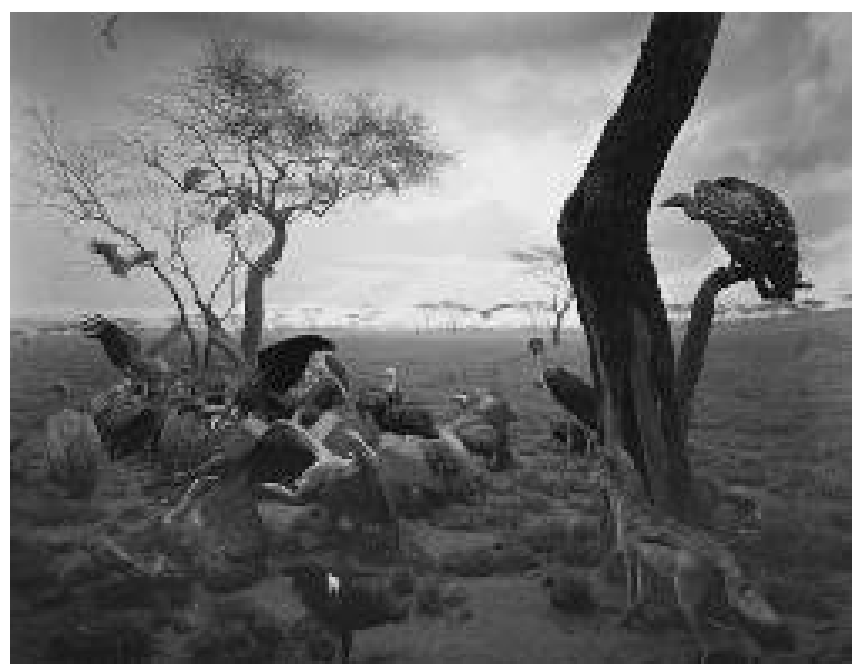

Figura I - Hyena-jackel-vulture 1976. Fonte: Sugimoto ([1974?]).

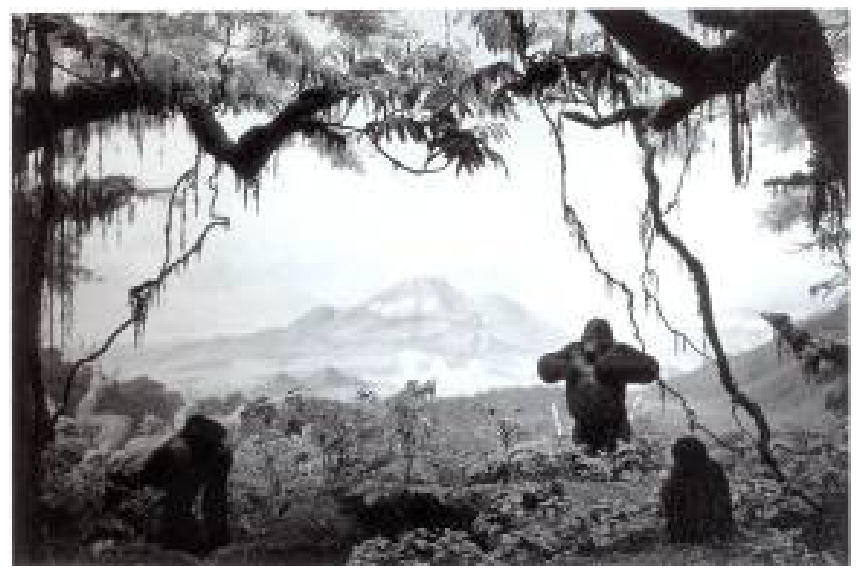

Figura 2 - Gorillas, 1994.

Fonte: Spector (2000).

O que nos parece indicativo de seu profundo envolvimento com os mecanismos do fazer fotográfico é que, em seu primeiro trabalho autoral, Sugimoto já se debruça sobre um recurso de representação que possui uma correlação muito estreita com a fotografia.Vejamos a seguir. 


\section{A invenção do Diorama}

As origens dos Dioramas datam da primeira metade do século XIX. Jacques Mande Daguerre (I789-|85I) antes de se estabelecer como um dos principais inventores da fotografia, por meio da célebre técnica do daguerreótipo, patenteou o Diorama em 1822 como um "método de exibição de imagens" (WOOD, I857, p. I).

Daguerre foi montador, pintor e decorador de cenários teatrais. Profundo conhecedor de efeitos luminosos, se associou a Charles Bouton (I78I - 1853) para montar: "um monumento de exposição de efeitos da pintura (visível durante o dia) com a denominação de Diorama"” (WOOD, 1997, p. 35, tradução nossa).

O primeiro Diorama, foi inaugurado por Daguerre e seu sócio em Paris, no bairro "Fauberg du Temple". No local de exposição, o público, maravilhado, podia observar imagens imensas (cerca de 20XI3 metros) de cenários naturais, construídos por meio de intrincados sistemas de iluminação e pintura. As pessoas ficavam sentadas em cadeiras fixas no interior de um anfiteatro, sobre uma plataforma que girava em torno de um eixo em 360 graus.

Os novos teatros de exibição de imagens de Daguerre também foram construídos na Inglaterra. Abaixo, apresentamos uma imagem que ilustra o funcionamento deste intrincado mecanismo de apresentação ilusionística:

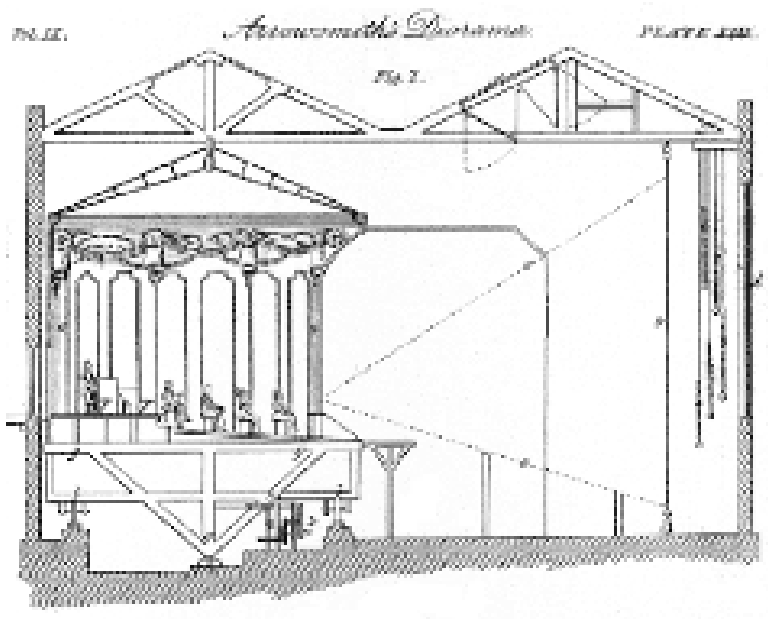

Figura 3 - Plano transversal do Diorama construído em Londres.

Fonte:Wood (1993).

O ilusionismo ótico era produzido através da utilização de pinturas feitas sobre material translúcido. Com a utilização de um intrincado sistema de luzes, combinando efeitos de reflexão e refração; sombras e tonalidades realísticas emergiam frente aos espectadores.A ilusão de tridimensionalidade era surpreendente.

Confortavelmente sentado, o público observava mudanças na imagem que ia variando gradativamente, simulando aspectos naturais de mudança de tempo e clima. $O$ teatro de atrações da visão construído por Daguerre atraiu

4 “Un monument d'exposition d'effets de peinture (visible pendant le jour) sous la dénomination de Diorama" (WOOD, 1997, p. 35). 
um público considerável durante o seu funcionamento. Em Paris, durante os anos mais prósperos, foram contabilizados cerca de 80.000 visitantes, resultando em um negócio bastante lucrativo no comércio das atrações do ilusionismo. Para a época, esse número de espectadores é consideravelmente grande.

Ironicamente, o Diorama construído por Daguerre em Paris foi destruído por um incêndio em 1839; apenas três meses após a invenção da técnica que o tornaria um dos mais famosos inventores da fotografia - o daguerreótipo.

\section{Os Dioramas nos Museus de História Natural}

A atração pelos Dioramas foi retomada novamente ao final do século XIX por Museus de História Natural, sobretudo nos Estados Unidos.Algumas mudanças, contudo, devem ser demarcadas.

Os Dioramas, nos Museus de História Natural dos Estados Unidos, são denominados Habitat Dioramas (Dioramas de Habitat Natural) e combinam conhecimento científico sobre espécies do reino animal e vegetal com técnicas de reprodução de cenários naturais.

Além da reprodução de paisagens em superfícies bidimensionais, há também a introdução de elementos tridimensionais: animais empalhados, reprodução de organismos minerais e vegetais que, combinados, conferem à cena um caráter de realismo.

Assim, os Dioramas dos Museus de História Natural oferecem a seus freqüentadores uma espécie de viagem no tempo e no espaço. Os observadores, antes restritos às cadeiras, movimentam-se agora livremente, em frente aos Dioramas, devidamente protegidos por vidros transparentes.

Os Habitat Dioramas do Museu de História Natural de Nova lorque são considerados como uma das principais atrações. Nos salões dos Habitat Dioramas, pode-se observar também a presença de peças de reprodução de animais fora dos vidros.

\section{"Ver através de"}

Steve Quinn, administrador de projetos do Museu de História Natural de Nova lorque salienta em uma entrevista, o significado do termo "Diorama”, inventado pelo próprio Daguerre: “A palavra Diorama é derivada das expressões gregas: dia 'através' e horama 'como é visto'. Portanto poderia ser traduzido como: 'ver através de' "5 (QUEEN, [2009?], tradução nossa).

O significado do termo, interpretado à luz da técnica desenvolvida por Daguerre durante o século XIX, implica em uma observação da natureza "através de" mecanismos de reprodução da luz e da paisagem.

Com a introdução dos Dioramas nos Museus de História Natural, a expressão "ver através de" toma novas configurações. Os cenários tridimensionais são observados "através dos vidros" - o primeiro elemento inserido entre o olhar do espectador e a reprodução da natureza. O vidro, aqui, simboliza uma interface entre o olhar e o que está guardado em seu interior - "ver através" do vidro implica uma forma específica de observação.

5 "The word diorama is from Greek: dia 'through' and horama 'as is seen'. So it could be translated roughly as 'to see through" (QUEEN, [2009?]). 

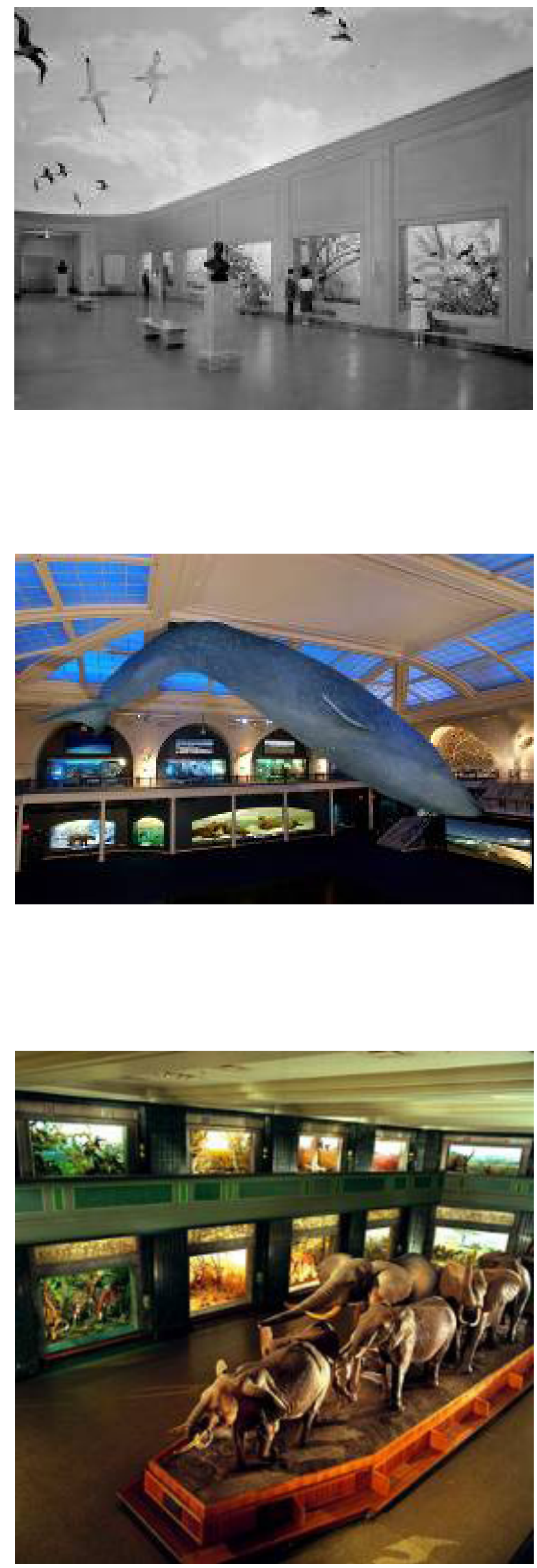

Figura 4 - O "Whitney Memorial Hall" no Museu de História Natural de Nova lorque exibe a vida dos pássaros do Pacífico. Fonte: Coles e Bierwert (1939).

Figura 5 - Salão da vida marinha. Museu de História Natural de Nova lorque.

Fonte:American Museum of Natural History (2003).

Figura 6 - Salão de mamíferos africanos.

Museu de História Natural de

Nova lorque.

Fonte:American Mu-

seum of Natural History ([1936?]) 
Neste sentido, Screech em sua obra "The Western Scientific Gaze and Popular Imagery in Later Edo Japan” (1996, p. I 34), esclarece de maneira instigante concepções da visão ocidental, ao compará-la com as ideias dos japoneses sobre como o mundo deveria ser visto. Ao comparar as duas maneiras de enxergar o mundo, ficam claras as distinções e características próprias da visão ocidental que foram rapidamente incorporadas pelos japoneses.

Screech observa que a introdução do vidro durante o Período Edo (1603 - 1868) na sociedade japonesa, modificou a relação do olhar do observador com o que era observado. Olhar algo através do vidro implica um distanciamento entre observador e observado. Observar uma espécie contida no vidro reforça uma tradição ocidental do olhar, ao objetificar e tornar científico o que é observado. Bosi (1988, p. 77) em "Fenomenologia do olhar": "O olho do racionalismo clássico examina, compara, esquadrinha, mede, analisa, separa [...] mas nunca exprime. É um olho capaz de perceber, no objeto, a sua objetualidade; logo tudo tratar como objeto, não sujeito."

Com a introdução do vidro no Japão, Screech (1996) ressalta uma verdadeira mania durante o século XVIII de preservação de espécies animais dentro de recipientes de vidro, embebidas em fluidos embalsamadores. No interior do vidro, as espécies se tornam:"permanentemente resguardadas do exterior e eternamente visíveis" (SCREECH, 1996, p. 143). (figuras 7 e 8 )

O interior do vidro simboliza um local ideal para a observação cientificista; em seu isolamento, a espécie se oferece para a observação racional e os estudos minuciosos. De maneira análoga, nos museus, conjuntos de peças taxidérmicas são tradicionalmente expostas no interior de cubos de vidro.

Assim, os "Dioramas de Habitat Natural" configuram-se como uma espécie de versão mais sofisticada destas primeiras exposições, como se observa na Figura 9.

Este tipo de exposição, onde as espécies animais encontram-se isoladas no interior de recipientes de vidro, foi gradativamente sendo modificada para incluir outros elementos na composição. (Figura 10)

O vidro transformou-se em uma espécie de janela, através da qual as espécies animais e as características naturais dos habitats poderiam ser observadas.

Phillip Fraley, do Museu de História Natural de Los Angeles, ressalta que os Dioramas de Habitat Natural contemporâneos são compostos por três características fundamentais: o primeiro plano (geralmente composto por reproduções de plantas e outras espécies); o elemento principal sobre o qual recai nossa atenção (reprodução de alguma espécie do reino animal ou vegetal) e, finalmente, o plano de fundo (constituído por uma pintura sobre um suporte curvo) (HABITAT VIEWS PART I). (Figuras II a I4)

A introdução de elementos tridimensionais e a relação de diferentes proporções entre os planos reforçam a sensação de perspectiva. Por outro lado, os fundos pintados sobre suportes curvos permitem a livre movimentação do visitante e a observação dos Dioramas através de vários ângulos de visão.

A seguir, dois exemplos de Dioramas do Museu de História Natural onde se observa, claramente, o fundo pintado e o efeito de perspectiva e de tridimensionalidade. 

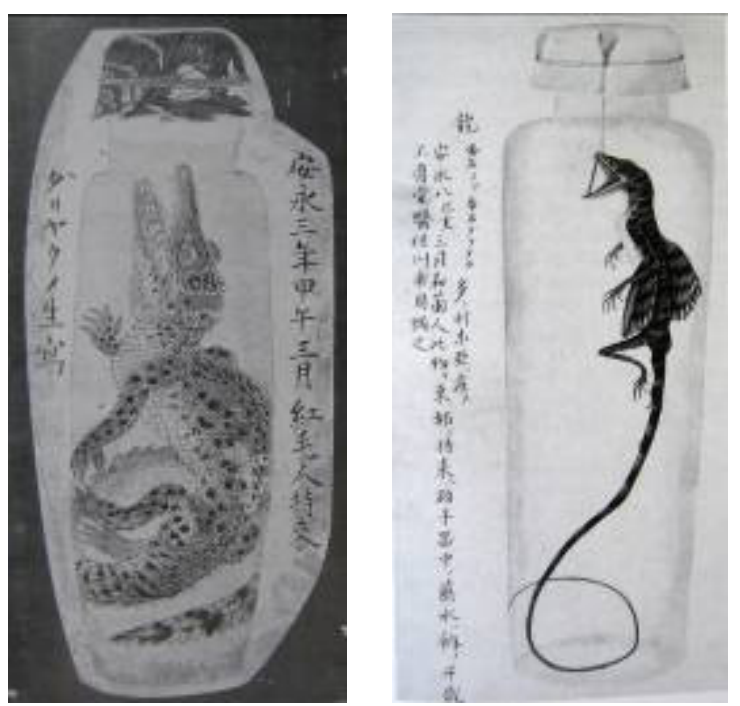

Figura 7 - Hosokawa Shigekata, 1760.

Fonte: Screech

(1996).

Figura 8 - Satake Yoshiatsu (Shozan), I 778.

Fonte: Screech

(1996)

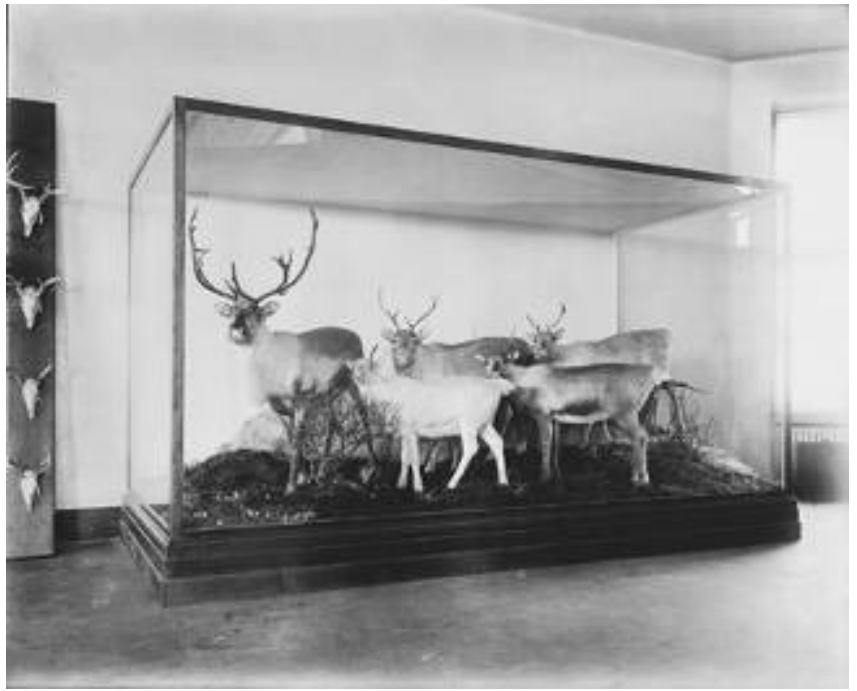

Figura 9 - Um exemplo antigo de "Habitat Coletivo", a partir do qual o Diorama se desenvolveu. (c.1900).

Museu de História Natural de Nova lorque.

Fonte:American Museum of

Natural History

([1900?].

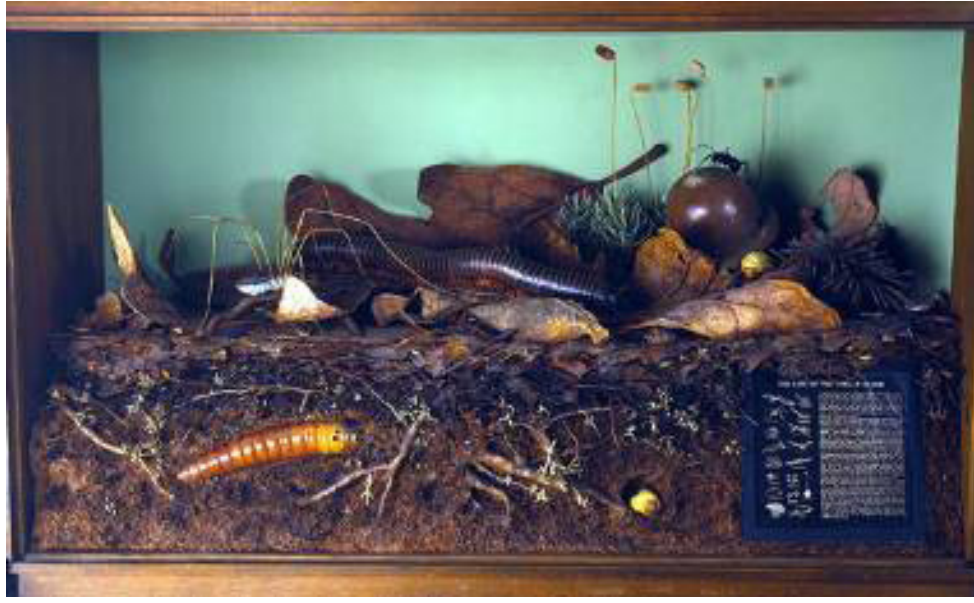

Figura 10 - O chão da

floresta.

Museu de História

Natural de Nova

lorque.

Fonte: Rota

(1958). 


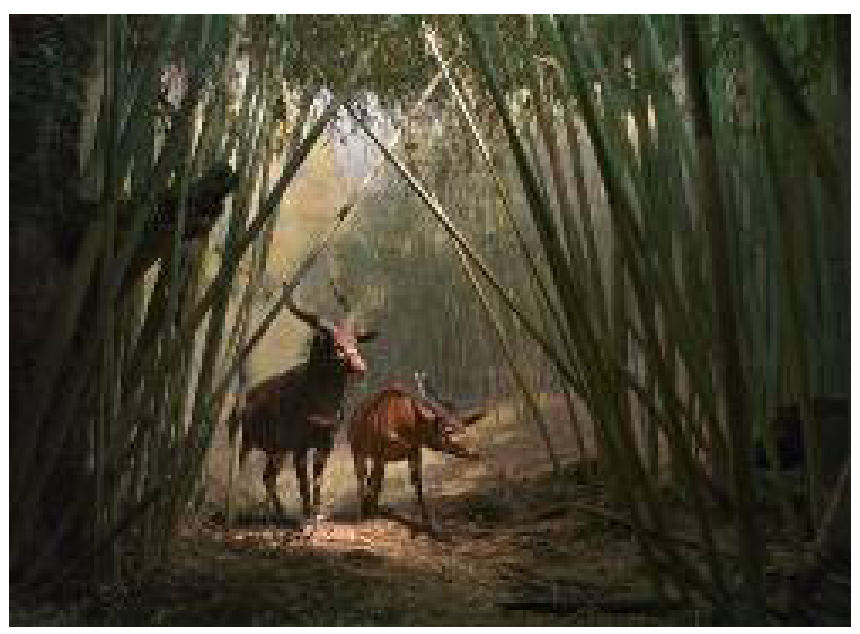

Figura II - Bongo.

Salão de mamíferos africanos.

Museu de História Natural

de Nova lorque.

Fonte: Rice e Bierwert

(1935).

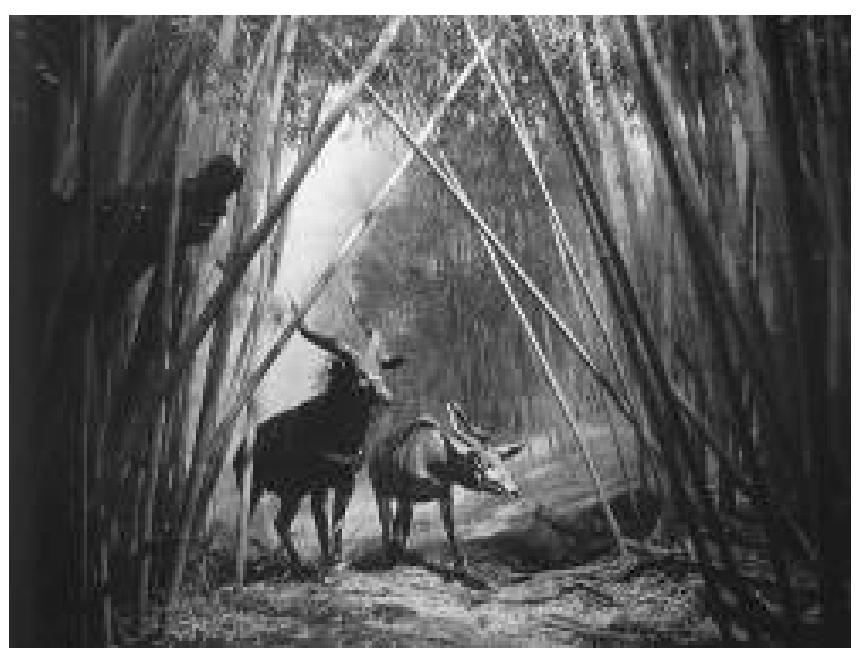

Figura 12 - Bongo.

Fotografia de Hiroshi Sugimoto

Fonte: Brougher (20I0).

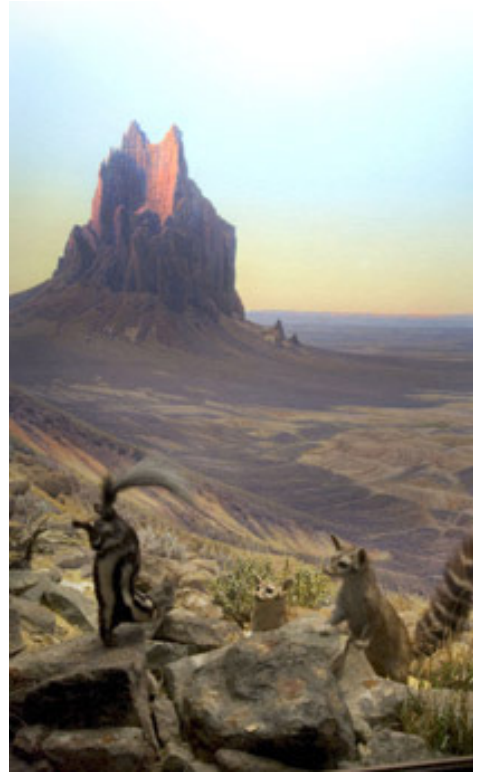

Figura I 3 - Gambá e Cacomistle. Salão de Mamíferos Norte Americanos. Fonte: McMorrow (2007).

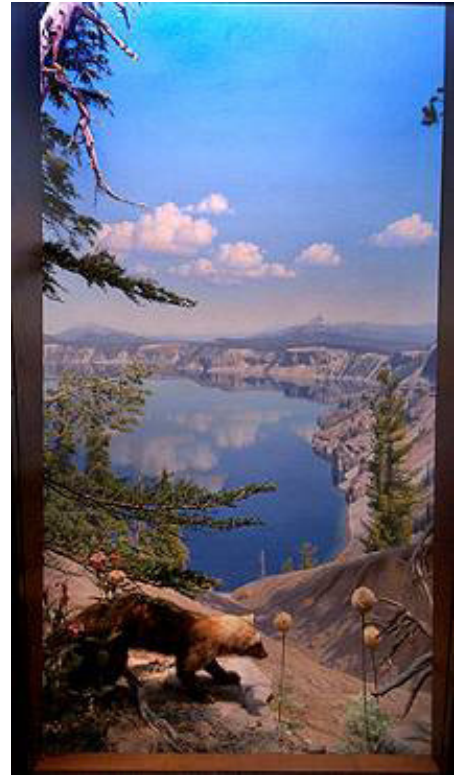

Figura 14 - Pine marten. Salão de Mamíferos Norte Americanos. Fonte: McMorrow

(2007) 


\section{Sugimoto observa os Dioramas}

Ao chegar em Nova lorque em 1974, fiz passeios turísticos. Eventualmente eu visitei o Museu de História Natural onde fiz uma descoberta curiosa: os animais empalhados posicionados frente aos fundos infinitos pintados pareciam extremamente artificiais. Porém, ao fechar um dos olhos e dar uma rápida olhada, toda a perspectiva artificial desaparecia e de repente, tudo parecia muito real. Eu havia descoberto uma maneira de enxergar o mundo do mesmo jeito que uma câmera fotográfica enxerga. Por mais artificial que fosse o objeto, uma vez fotografado, é como se ele se tornasse real ${ }^{6}$ (SUGIMOTO, [1974?], tradução nossa).

Sugimoto ([1974?]) relata, ao observar os Dioramas, o caráter de artificialidade dos animais posicionados frente aos fundos infinitos. A seguir apresentamos técnicas comumente utilizadas na representação da perspectiva bidimensional que foram adaptadas na construção dos Dioramas, reforçando a perspectiva que tanto incomodava Sugimoto, antes de fechar um dos seus olhos.

Obedecendo a leis geométricas, a representação do espaço em perspectiva é traçada por meio de linhas diagonais concêntricas que convergem ao chamado "ponto de fuga" e pela distribuição de proporções em escala das figuras representadas. Para reforçar a sensação de perspectiva, deve haver diferença de luminosidade entre os planos e falta de definição do plano de fundo (frequentemente pintado em azul). Vejamos o Diorama dos Gorilas fotografado por Sugimoto, nas figuras 15 e 16.

O Diorama dos Gorilas é considerado uma das representações de destaque do Museu de História Natural de Nova lorque. O distanciamento entre os planos é reforçado pelo contraste de luminosidade e definição entre os elementos em primeiro plano - troncos e vegetação- e aqueles ao fundo (em tom azulado) - animais, montanhas e nuvens. Neste Diorama, percebemos claramente a existência de linhas diagonais concêntricas, convergindo para um ponto de fuga localizado no cume da montanha do plano de fundo.

Ostrower (2004, p. 7I) ressalta que linhas diagonais traçadas na imagem, vistas em conjunto com as horizontais e as verticais introduzem também a dimensão de profundidade.Vejamos como estas linhas poderiam ser traçadas neste Diorama, conforme figura 17.

As linhas demarcadas se configuram como mais um indicador de relação de tridimensionalidade entre os elementos que compõe o diorama. De fato há uma diversidade de direções nas linhas, reforçando volume e perspectiva na cena.

Ostrower (2004) segue ressaltando que superposições e relação entre espaços “cheios/vazio" - são características espaciais próprias da tridimesionalidade. Assim, no Diorama dos Gorilas, percebemos a relação de superposição entre um espaço que aparece repleto de elementos nos planos mais próximos ao observador (galhos, troncos, vegetação e animais), em contraste com o plano de fundo - praticamente vazio, isolado em sua representação clara e nebulosamente indefinida.

6 "Upon first arriving in New York in 1974, I did the tourist thing. Eventually I visited the Natural History Museum, where I made a curious discovery: the stuffed animals positioned before painted backdrops looked utterly fake, yet by taking a quick peek with one eye closed, all perspective vanished, and suddenly they looked very real. I'd found a way to see the world as a camera does. However fake the subject, once photographed, it's as good as real" (SUGIMOTO, [1974?]). 


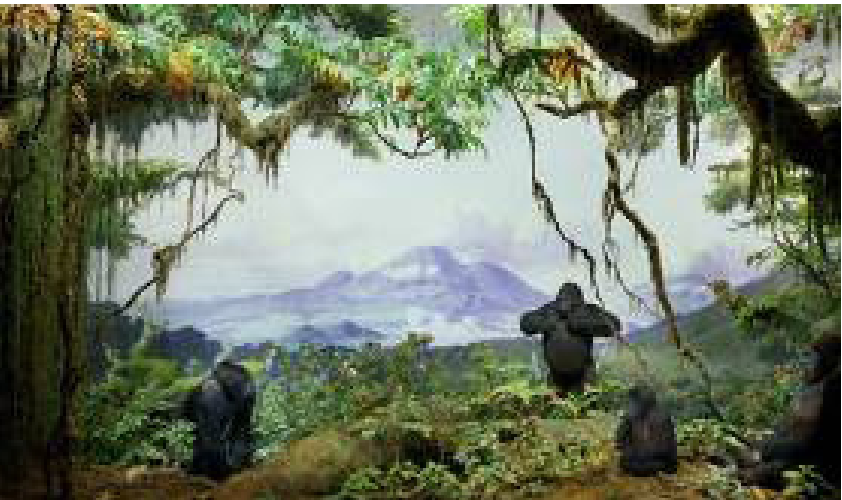

Figura 15 - Diorama dos Gorilas. Museu de História Natural de Nova lorque.

Fonte:American Museum of

Natural History ([1936?].

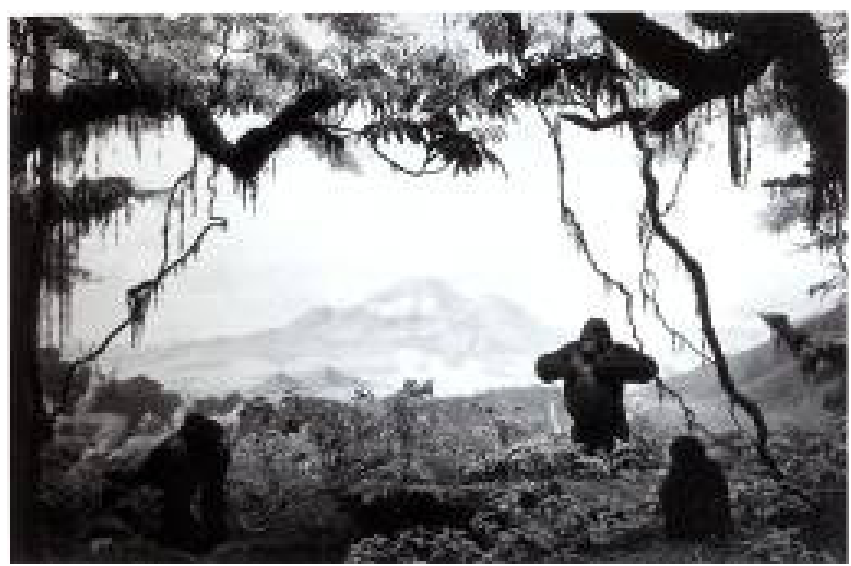

Figura 16 - Gorillas

Museu de História Natural de Nova lorque.

Fotografia de Hiroshi Sugimoto.

Fonte: Spector (2000).

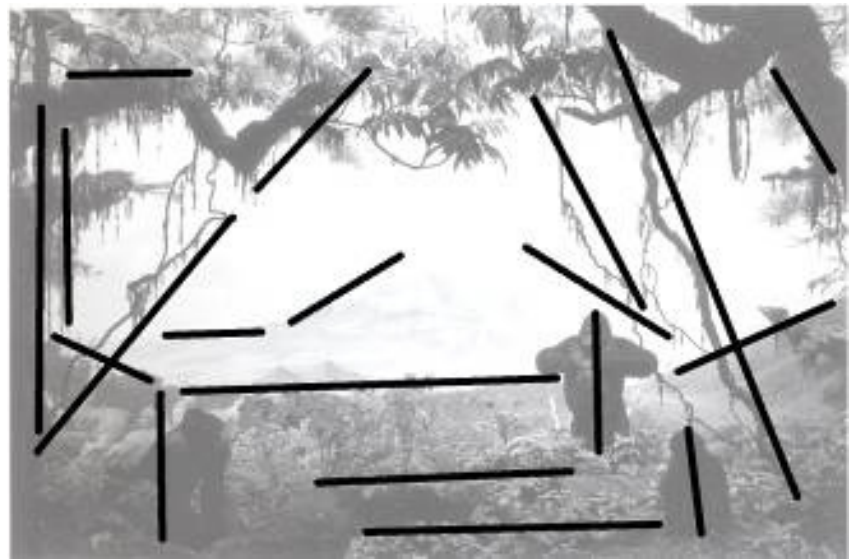

Figura 17 - Linhas diagonais, horizontais e verticais traçadas sobre a fotografia de Hiroshi Sugimoto Fonte: A autora. 
Se a observação "in loco" com os dois olhos, experimentada por Sugimoto sugere um certo exagero ou superlativo de real, é justamente porque a visão binocular nos traz, a todo momento, a sensação de profundidade dos objetos no espaço.A visão binocular, também denominada visão estereoscópica é resultado da associação de imagens de cada um dos nossos olhos, resultando em uma percepção do campo visual em três dimensões (RUDOLPH; MUELLER, 1968, p. 8I). Sugimoto (2006, tradução nossa) relata a experiência de observação dos Dioramas:"Temos dois olhos e não somente um olho portanto [...] se você observa os Dioramas com os dois olhos, instantaneamente, você percebe os planos como se estivesse posicionado a três metros, mas quando você fecha um dos olhos, você perde a percepção do plano de fundo". ${ }^{7}$

Para Sugimoto (2006), é justamente através da fotografia que o estranhamento se desfaz e os Dioramas adquirem a aparência de realidade.A dissimulação estética se desfaz por meio de um ato fundamental - fechar um dos olhos:"[...] ao fechar um dos olhos e dar uma rápida olhada, toda a perspectiva artificial desaparecia e, de repente, tudo parecia muito real."8 Enxergando - mundo da mesma maneira que uma câmera fotográfica, Sugimoto (2006) atesta: "Por mais artificial que fosse o objeto, uma vez fotografado, é como se ele se tornasse real." "

Assim, ao observar os Dioramas com apenas um dos olhos, os planos sofrem um nivelamento, a configuração do espaço toma contornos bidimensionais e, para o fotógrafo, esse tipo de configuração se torna mais próximo daquilo que ele concebe como "realidade".

Desta forma, a visão monocular de Sugimoto, tal qual a lente de uma máquina fotográfica, organiza "verdadeiramente" o espaço diante do seu olho. Enxergar monocularmente transforma o olho de Sugimoto em um instrumento captador da imagem análogo a um aparelho ótico, mais especificamente à lente de uma câmera. Contidos no interior do vidro; transformados em imagem fotográfica pelo olhar monocular de Sugimoto, os animais e a paisagem convertem-se em objetos de observação científica. $O$ real parece, assim, estar muito mais presente enquanto conceito do que como uma maneira específica de enxergar. Porém, a afirmação de Sugimoto contém algumas contradições: enxergar monocularmente um ambiente construído em perspectiva não basta. A artificialidade do Diorama parece subsistir. $O$ Diorama dos Gorilas requer uma observação mais atenta.

\section{O superlativo de real no Diorama dos Gorilas.}

A linguagem de cognição estruturada pelos cenários do Diorama reforça a tradição dos Teatros construídos originariamente por Daguerre: a de provocar um deslumbramento nos espectadores diante do que é observado.

Este tipo de atração em relação à visão do ambiente natural, remonta às origens da fotografia de natureza e de animais. Ao denotar o mundo, a fotografia possui como principal objetivo um caráter quase que didático -

\footnotetext{
7 "We have two eyes and not just one eye, so ... if you look at the Diorama with two eyes you instantly measure the backdrops as ten feet away but when you close one eye, you lose this sense of depth" (SUGIMOTO, 2006).

8 " [...] Yet by taking a quick peek withone eye closed, all perspective vanished, and suddenly they looked very real" (SUGIMOTO, 2006).

9 “However fake the subject, once photographed, it's as good as real” (SUGIMOTO, 2006).
} 
ensinando aos espectadores quais elementos integram o "real". Os fotógrafos se constituem como testemunhas oculares dos fatos e das cenas mais surpreendentes e estruturam a imagem da natureza como um registro científico - a verdade da paisagem.

Ora, Phillip Fraley, vice-presidente do Museu de História Natural de Los Angeles, caracteriza os Dioramas enquanto "registro":"Estes se tornaram os únicos registros que temos", Fraley também parece ter sido confundido por uma espécie de trompe-l'oeil (efeito de ilusão de ótica) do cenário. A visão dos observadores dos Dioramas sofre uma espécie de catequização: a realidade "natural" seria constituída tal qual aparece representada nos cenários.

Ora, a própria estruturação da linguagem fotográfica e dos credos associados a esse tipo de imagem tem um caráter didático e demonstrador. Assim como se aponta uma máquina para a realidade, apontam-se as imagens, através do dedo do fotógrafo, do cientista ou do técnico, que atesta para o observador o olhar monocular: aqui está o real.

Mas, este credo sobre a denotação da imagem é uma verdade fabricada, uma realidade ilusionística. Se as primeiras imagens mostradas para o público frequentador dos Teatros do Diorama eram montadas através de intrincados sistemas de ilusionismo ótico, o trabalho dos criadores dos Dioramas, nos Museus, também confirma uma produção sofisticada; uma montagem exaustiva do que é alçado à categoria de "realidade".

Nesse sentido, ao observarmos o Diorama dos Gorilas, percebemos justamente a utilização dos clichês mais fundamentais da fotografia e da representação em perspectiva. $O$ cenário parece realizar um movimento de auto-explicação, reafirmando muitas das regras de composição utilizadas com frequência em manuais de fotografias que nos ensinam, com uma didática repetitiva, "como tirar uma boa foto".

O Dioramas dos Gorilas talvez seja a combinação ideal entre visão fotográfica e cientificismo colecionista, em um cenário artificialmente "natural". O superlativo de real se estrutura de forma pungente nesse paraíso dos primatas.

Nesse sentido, na cena parada, temos a morte/congelamento dos animais, o fundo em perspectiva, a cena denotadora de hábitos dos gorilas uma espécie de cenário fotográfico em três dimensões, congelado para uma posteridade de frequentadores do museu. Além da exagerada tridimensionalidade, o cenário é estruturado para um olhar que observa um mundo oticamente construído. $O$ estranhamento, contudo, surge de algumas combinações improváveis no universo da fotografia, como veremos mais adiante.

Representar um cenário natural significa uma espécie de congelamento temporal do espaço. $O$ registro de um ambiente através da máquina fotográfica transforma o que é real em dados representativos. Preservado estaticamente, o ambiente natural estrutura-se como paisagem, vista. É um ambiente propício para a observação científica.A relação entre estética e cientificismo, arte e técnica, nos parece bastante clara neste cenário; ao adquirir um caráter imagético, o ambiente natural entra em uma esfera de observação e entendimento que combinam fruição estética, conhecimento e didática cientificista. Ao entrar para o universo da representação, o Gorila sai do mundo natural para se transformar em um registro.

Vejamos, a seguir, algumas correlações entre os mecanismos do fazer fotográfico e a construção do Diorama dos Gorilas. (Figura 18) 
Este Diorama é considerado justamente como uma das atrações principais do Museu de História Natural de Nova lorque e foi concebido por Carl Akeley; explorador, conservacionista, taxidermista, escultor, cinegrafista e fotógrafo. Akeley foi uma espécie de mentor dos Dioramas do Museu de História Natural de Nova lorque.

Suas experiências estão reunidas no livro:"In brightest Africa” (AKELEY, 1920). O livro é uma espécie de diário de bordo, relatando todas as aventuras nas expedições em busca de espécies para compor os Dioramas do Museu de História Natural de Nova lorque, no início da década de 20.

$\mathrm{Na}$ época, era comum buscar espécies "in loco" para o acervo dos Museus europeus e americanos. Inspirado pelo espírito colecionista, Akeley partiu para uma expedição ao Congo Belga, na área dos vulcões Kivu, em busca de espécies de gorilas para compor o mais famoso Diorama do Museu de História Natural de Nova lorque.

Akeley foi acompanhado por um grupo de assistentes nativos com bom conhecimento da área, para caçar, filmar e fotografar os gorilas.Apesar de experimentar um sentimento de remorso por matar gorilas (AKELEY, 1920, p. 217), em nome da preservação científica, abateu os três animais que hoje estão em exposição no Diorama. Após o abate do animal, o time de assistentes contratado por Akeley entrava em ação, retirando a pele e os ossos do gorila para a reconfiguração taxidérmica. Para preservar os traços fisionômicos exatos dos animais abatidos, Akeley confeccionava máscaras mortuárias. (Figura 19)

A questão da preservação fidedigna de cada uma das espécies era fundamental. As peças taxidérmicas eram formadas de uma escultura construída a partir do esqueleto e das dimensões originais do animal. Em sua saga de preservação realista,Akekey (1920, p. 2 I I) empreendia um trabalho exaustivo: fotografava o conjunto dos ossos do animal, os pés, as mãos e a cabeça, confeccionava uma máscara mortuária, preservava o cérebro, os órgãos internos e o couro do animal e registrava inúmeras medidas.

O trabalho era denominado por Akeley (1920, p. 2II) de "scientific collecting" ("colecionismo científico"). Para uma boa preservação do animal havia a necessidade de tirar a pele, limpar, medir, preservar e fazer anotações; tudo de uma só vez.

A maneira como Akeley (1920, p. 220) narra a caçada aos gorilas é extremamente parecida com a forma como descreve a filmagem e registro fotográfico dos animais. A sequência básica tanto para o registro de imagens quanto para a caça era sempre a mesma: seguir as pegadas, avistar os animais, chegar o mais próximo possível e mirar - a câmera ou a arma.

Akeley (1920, p. 220) aproxima o ato da caça à captura de imagens e se refere à expedição de filmagem como:"Caçada ao gorila com a câmera de movimento" 10 .A caçada às imagens dos gorilas retira-os de seu ambiente natural para transpô-las a uma esfera representativa. Mortos, são representados em um teatro fotográfico pseudo-naturalista.

Além da coleta das quatro espécies representadas no Diorama, a expedição de Akeley tinha como objetivo reunir diferentes elementos para a construção do cenário. Houve uma preocupação com a seleção de um plano 


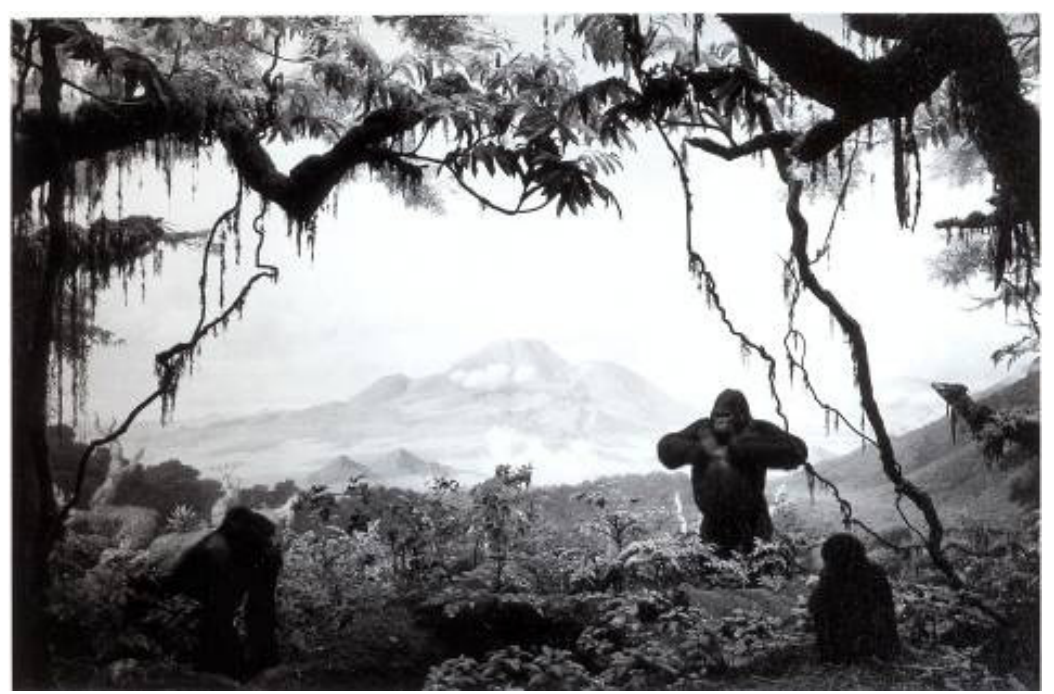

Figura 18 - Diorama dos Gorilas. Fotografia de Hiroshi Sugimoto.

Fonte: Spector

(2000).

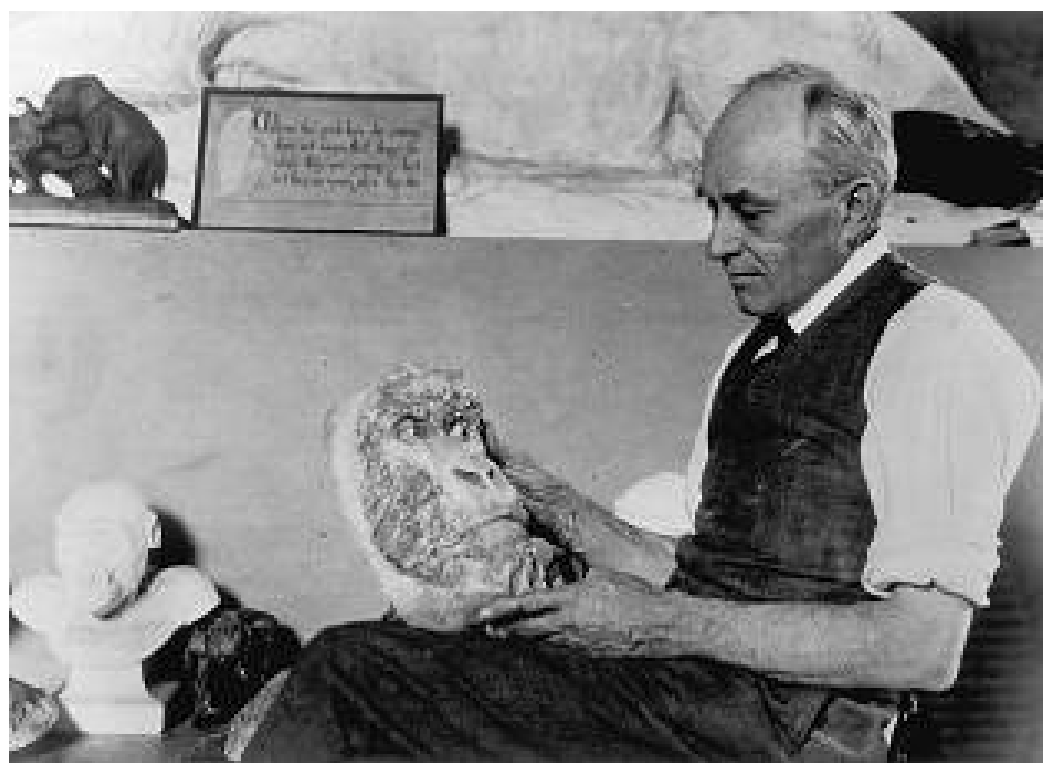

Figura 19 - Carl Akeley e a máscara mortuária de um dos gorilas abatidos.

Fonte:Akeley

(1924). 
de fundo interessante para compor o Diorama. Akeley realizou uma filmagem em panorâmica das montanhas que compõem o plano de fundo do cenário e a reprodução em tinta no plano de fundo foi realizada no retorno ao Museu, a partir da cena filmada.

A análise do Diorama de Akeley suscita questões intrigantes, sobretudo quando analisadas do ponto de vista da fotografia realizada por Sugimoto.Vejamos.

O resultado da composição fotografada por Sugimoto foi de uma cena que nunca existiu. $\bigcirc$ resultado imagético, na verdade, retoma uma idéia elaborada por Carl Akeley. Mesmo que Sugimoto ([1974?]) afirme: "Por mais artificial que fosse o objeto, uma vez fotografado, é como se ele se tornasse real" um certo estranhamento da visão ainda persiste. Toda a composição elaborada cuidadosamente por Akeley, deixa entrever características visuais que, quando reunidas, sugerem a artificialidade, o superlativo de real.

Sugimoto, por sua vez, em sua saga por uma fotografia que comenta seu próprio status ontológico, procura exagerar o tom de realismo reproducionista ao extremo, escolhendo a abertura de diafragma mais diminuta possível para este tipo de fotografia. $O$ efeito é uma imagem com muita profundidade de campo e detalhes precisos, do primeiro plano ao plano de fundo. $O$ resultado gera uma imagem totalmente incompatível com uma fotografia de gorilas em seu ambiente natural, justamente pela fidedignidade e pelo excesso de detalhamento em todos os planos. A fotografia remete a um realismo impossível, voltando-se como um comentário irônico sobre a própria impossibilidade de duplicação do real.

Brougher em seu texto "Impossible photography" (2010, p. 20) ressalta um dado fundamental sobre o estranhamento visual das fotografias dos Dioramas: toda a cultura visual sobre a representação de animais ferozes se apóia em fotografias realizadas com lentes teleobjetivas.

Ora, uma das obsessões de Akeley era conseguir uma fotografia dos Gorilas de forma bem próxima. Em seu diário de expedição ele relata:"Seria muito grafiticante se eu conseguisse fazer uma fotografia a uma distância de seis metros" "I (AKELEY, 1920, p. 197, tradução nossa). Tal proximidade de um bando de gorilas seria no mínimo perigosa.

Ao pesquisarmos na internet fontes de imagens e vídeos sobre essas criaturas, os resultados mais frequentes são fotografias em close de rostos de gorilas, combinadas com filmagens realizadas a uma distância de segurança dos animais - em sua vasta maioria com a utilização de lentes teleobjetivas. A utilização da lente teleobjetiva gera, como resultado visual, uma menor profundidade de campo, com pouco detalhamento no plano de fundo. A maioria das fotografias encontradas ressalta closes e expressões faciais dos gorilas. (Figuras 20 a 22)

Por outro lado, encontradas de forma menos frequente, fotografias de bando de gorilas são realizadas com enquadramentos mais fechados, em meio a uma vegetação densa. Observamos que, em todas as fotografias abaixo, os gorilas permanecem bastante próximos. (Figuras 23 a 25)

Ora, quando comparamos esses tipos de tomadas com a fotografia de Sugimoto, a artificialidade da composição salta aos olhos.

II "I shall feel very gratified if I can get a photograph at twenty feet" (AKELEY, 1920, p. 197). 


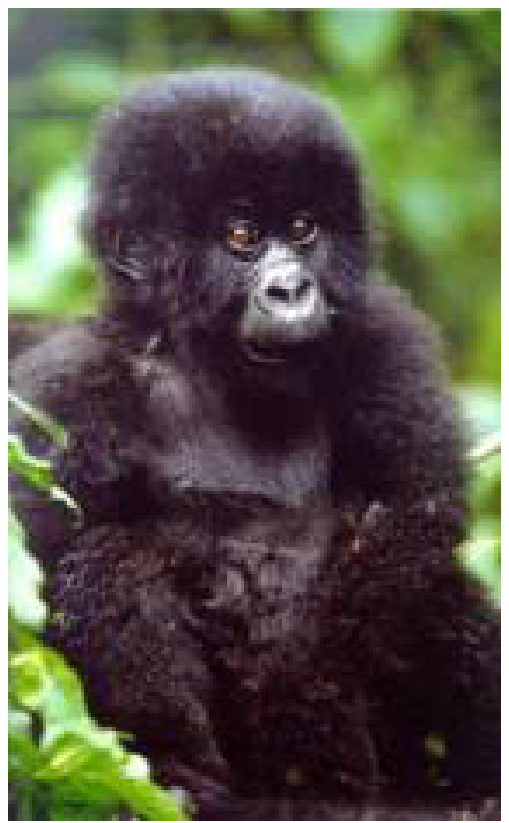

Figuras 20-22 - Fotografias mostrando closes e expressões faciais de gorilas.

Fontes: Fig. 20 - Satellites map volcanic... (2004);

Fig. 2 I - Moeller (2005);

Fig. 22 - Audley Burma Gallery (2008).
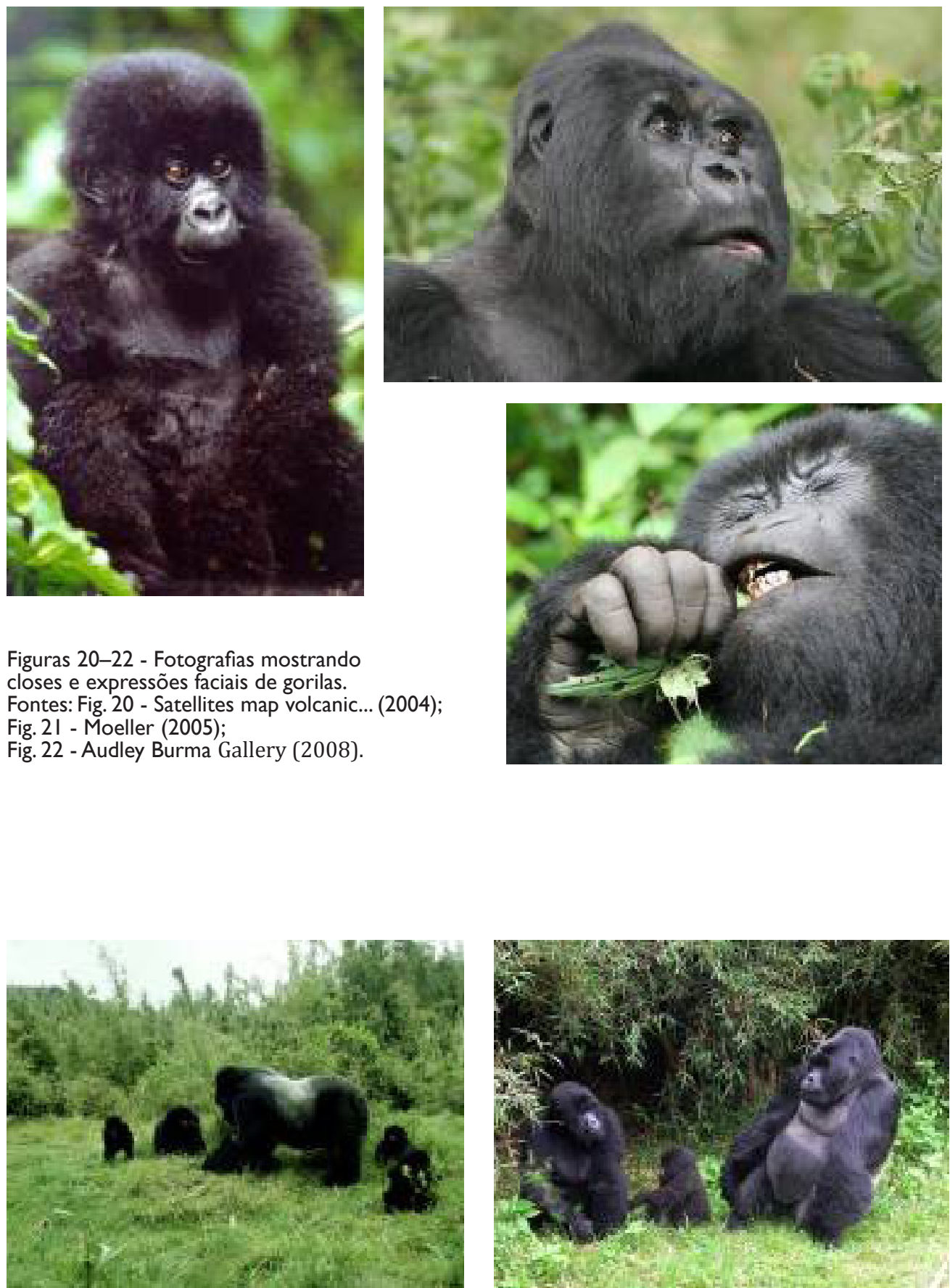

Figuras 23-25 - Bando de gorilas, fotografias com enquadramento mais fechado.

Fontes: Fig. 24 - Mountain gorilla family ([2008?]); Fig. 25 - Adventure trails([2000?]).

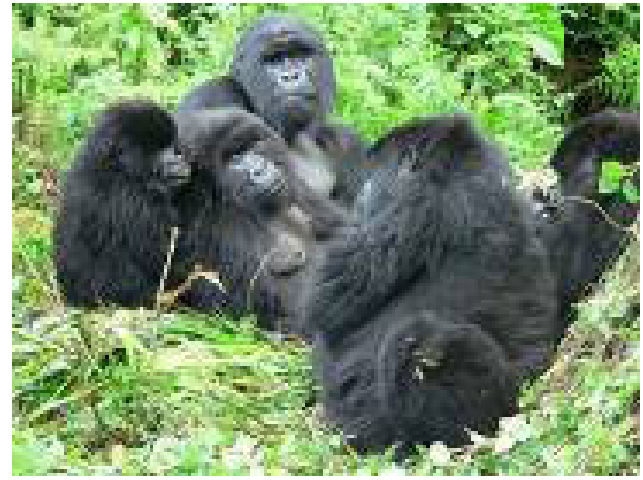




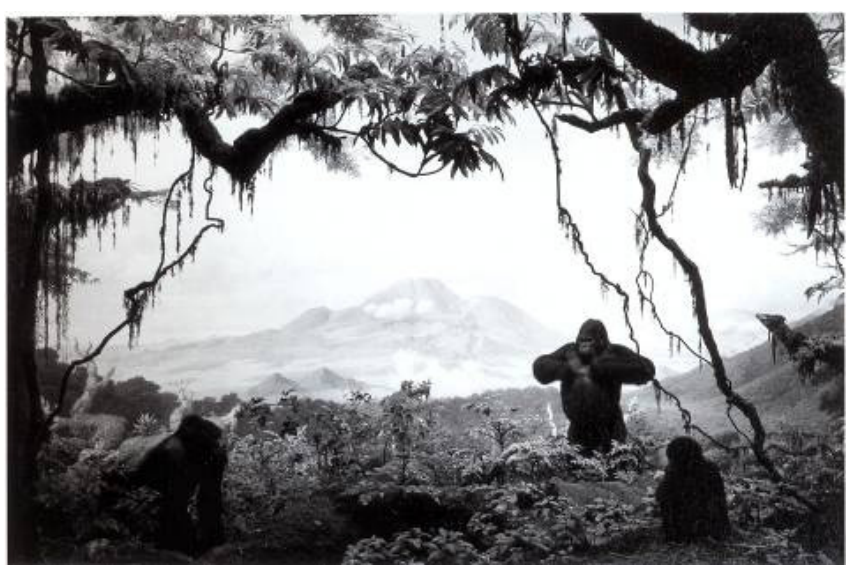

Figura 26 - Diorama dos Gorilas. Fotografia de Hiroshi Sugimoto. Fonte: Spector (2000).

Ao contrário do realismo que Sugimoto advoga, a fotografia parece extremamente artificial. Justamente porque se afasta do repertório imagético da cultura visual sobre imagens de gorilas construídas por outros fotógrafos. $O$ enquadramento aberto, o excesso de detalhamento em todos os planos, a distância entre os animais tornam a imagem estranhamente deslocada. $\mathrm{O}$ artificialismo salta aos olhos, por combinar um excesso de elementos representativos improváveis que, associados, geram uma visão idílica de uma espécie de paraíso dos gorilas, completamente diversa de registros fotográficos reais.

Observemos, também, o primeiro plano - um artifício extremamente ressaltado em manuais de fotografia- a criação de uma "margem" que emoldura o espaço percebido. A folhagem, os galhos e o cipó que emolduram graciosamente o cenário servem como elementos que direcionam nosso olhar para o que será observado. Há um cuidado estético análogo ao do drapeado das cortinas do teatro; as margens, na esfera representativa, reforçam para os observadores que o cenário é uma representação ficcional.

O fotógrafo utiliza os elementos que compõem o próprio cenário como moldura para o que será observado; o pano de abertura é a própria natureza - os galhos, troncos e folhagem emolduram a cena e dirigem o olhar do espectador para ela; o grau de "naturalismo" é ainda mais reforçado.

Se os antigos Dioramas de Daguerre representavam a exuberância da natureza e eventos históricos, no Diorama de Sugimoto temos a conjugação dessas duas instâncias. $\mathrm{O}$ ambiente natural é transformado em evento histórico: a ilustração de um bando da família dos gorilas em seu ambiente paradigmático - as montanhas africanas. Em um instante congelado, "momento decisivo", o gorila macho bate no peito. Uma das expressões claras de liderança sobre o bando e um sinal claro para o estranho que se aproxima - mantenha distância. A imagem grande angular de Sugimoto resulta num paradoxo: ela evidencia uma proximidade impossível.

A artificialidade da cena tem ainda mais um elemento: o plano de fundo. Nos escritos de Akeley (1920, p. 230), indica-se que o plano de fundo foi elaborado a partir de uma filmagem realizada em grande angular, após a morte de um gorila. Em um momento raro, a névoa que encobria com frequência o habitat natural dos gorilas havia desaparecido. De um local de visão privilegiada, o vulcão Mikeno foi enquadrado exatamente no ponto de fuga, no centro da composição. Sobre a paisagem, Akeley (1920, p. 230, tradução nossa) des- 
creve: “ [...] uma floresta ancestral de uma maravilhosa beleza, diferente de qualquer outra coisa que eu conheça, um verdadeiro reino encantado."'2.

Nesse sentido, até mesmo a paisagem no plano de fundo aparece como um excesso representativo. Justamente por se distanciar da configuração paisagística habitual da região - com frequência encoberta por uma névoa. A quimera visual fotografada por Sugimoto é de uma paisagem grandiloquente e impossível. O Diorama dos Gorilas é, antes de mais nada, um espaço de credos sobre a própria estrutura da representação fotográfica. A natureza repousa silenciosa, os elementos representativos estão todos em seu devido lugar - da margem ao plano de fundo. A estrutura da ação é congelada, a fantasia imaginativa de um momento decisivo da natureza.

O que é visto está cada vez mais distante do que concebemos como real. Afastado cada vez mais do realismo, Sugimoto fotografa uma quimera visual, apenas um teatro de atrações da visão, um bando de gorilas empalhados; a fantasia imaginativa de Carl Akeley.

\section{Referências}

ADVENTURETRAILS. Gorilla tours: mountain gorilla trekking trips in Uganda, Rwanda and Congo. [2000?]. Disponível em: <http://www.gorillatours.co.ug.>. Acesso em: 10 dez. 2010.

AKELEY, Carl Ethan. In brightest Africa. New York: Garden City, 1920. Disponível em: <http://www.archive.org/details/inbrightestafricakel>.Acesso em:05 mar. 201 I.

AKELEY, Carl. Carl Akeley contemplates plaster death mask of mountain gorilla. 1924. I fotografia. Disponível em: <http://www.stephencquinn.com/ AFC_expedition I I_archphotos.html>.Acesso em: I 6 jul. 201 I.

AMERICAN MUSEUM OF NATURAL HISTORY.Akeley hall of african mammals. New York, [1936?].

AMERICAN MUSEUM OF NATURAL HISTORY. Habitat group. NewYork, [1900?]. AMERICAN MUSEUM OF NATURAL HISTORY. The milstein hall of ocean life. New York, 2003. Disponível em: <http://www.amnh.org/exhibitions/ permanent-exhibitions/biodiversity-and-environmental-halls/milstein-hall-of-ocean-life>. Acesso em: 24 jul. 2012.

AUDLEY BURMA GALLERY. Mountain gorilla, Rwanda. 2008. I fotografia. Disponível em:<https://secure.audleytravel.co.uk/burma/view/C_RW_Mountain+g orilla+eating+stinging+nettles_0000 I46062_.jpg.html>.Acesso em:26 fev. 2010. BOSI,Alfredo. Fenomenologia do olhar. In: NOVAES, A. (Ed.). O olhar. 3. ed. São Paulo: Companhia das Letras, 1988.

BROUGHER, Kerry . Impossible photography. In: BROUGHER, Kerry; MULLER -TAM, Pia. Hiroshi Sugimoto. 2nd. ed. Ostifildern: Hatje Cantz, 20 I 0.

COLES, Charles H.; BIERWERT, Thane L. Visitors viewing dioramas, Whitney Memorial Bird Hall. New York: American Museum of Natural History, 1939. Disponível em: <http://images.library.amnh.org/photos/ptm/catalog/ desc/l65076/3>.Acesso em: I5 jun. 201 I.

DUBOIS, Philippe. O ato fotográfico e outros ensaios. 7. ed. Campinas:Papirus, 1993. HERSHBERGER, Andrew. The past, present and Future of the history of pho-

12 "There stretched a primeval forest of marvelous beauty - in character unlike anything else I know - a veritable fairyland” (AKELEY, 1920, p. 230). 
tography: interviews with Peter C. Bunnell, Gretchen Garner and Britt Salvesen. History of Photograhy, New York, v. 30, n. 3, p. 203-2I I, 2006.

MCMORROW, Brian J. Cacomistle, gallery of North American mammals. New York:American Museum of Natural History, 2007.

MIDLEY history of early photography: R. Derek Wood's articles on the History of early Photography, the Daguerreotype and Diorama.

MOELLER, Wolfgang. Mountain gorilla: silverback in volcanoes national park in Rwanda. 2005. I fotografia. Disponível em: <http://www.treknature.com/ gallery/Africa/Rwanda/photo38000.htm>. Acesso em: 30 jun. 2010.

MOUNTAIN gorilla family. [2008?]. I fotografia. Disponível em: <http://www. fanpop.com/spots/primates/images/489/35/title/mountain-gorilla-family-wallpaper>.Acesso em: 10 dez. 2010.

MUELLER, Conrad G; RUDOLPH, Mae. Biblioteca científica life: luz e visão. 2. ed. Rio de Janeiro: J. Olympio, 1968.

OSTROWER, Fayga. Universos da arte. 24. ed. Rio de Janeiro: Elsevier, 2004.

QUEEN, Stephen. Transcript: history of the diorama. [2009?]. Disponível em:

<http://www.amnh.org/exhibitions/virtual/bison/transcripts/diorama.php.> Acesso em: 05 fev. 2009.

RICE, H. S.; BIERWERT,Thane L. Bongo group, african hall. New York:American Museum of Natural History, 1935. Disponível em: <http://images.library.amnh. org/photos/ptm/catalog/desc/ I 4836 I/ I>. Acesso em: I 9 jul. 20 I I.

ROTA, Alex J. Display case, life on the forest floor exhibit, forestry hall. New York:American Museum of Natural History, 1958. Disponível em: <http://images. library.amnh.org/photos/ptm/catalog/desc/l 75004/3>.Acesso em: I 9 jun. 201 I .

SATELLITES map volcanic home of Africa's endangered gorillas. ScienceDaily, June, 2004. Disponível em: <http://www.sciencedaily.com/releases/2004/06/0406300827 I8.htm>.Acesso em: 26 jul. 20 I I.

SCREECH,Timon. The western scientific gaze and popular imagery in later edo japan: the lens within the heart. Ist. ed. New York: Cambridge University Press, 1996.

SUGIMOTO, Hiroshi. Dioramas. [S.I.: s.n.]: [1974?]. Disponível em: <www.sugimotohiroshi.com/diorama.html>. Acesso em: 03 abr. 2009.

SUGIMOTO, Hiroshi. Meet the artist: Hiroshi Sugimoto. [S.I.: s.n.], 2006. (Hiroshi Sugimoto Podcasts). Disponível em: <http://www.hirshhorn.si.edu/collection/sugimoto/\#detail=/bio/hiroshi-sugimoto-podcasts/\&collection=sugim oto>. Acesso em: 29 maio 2009.

WOOD, Derek.Arrowsmith's patent $n^{\circ} 4899$ : diorama, or method of exhibiting pictures. Midley History of Photography,London, n. 4899,p. I-7, I857.Disponível em: <http:// www.midley.co.uk/diorama/Diorama_Patent_2.htm:.Acesso em: I3 maio 2009.

WOOD, Derek. Daguerre and his diorama in the 1830s: some financial announcements. Photoresearcher, London, n. 6, p. 35-40, 1997. Disponível em: <http://www.midley.co.uk>.Acesso em: 06 abr. 2009.

WOOD, R. Derek. The diorama in Great Britain in the 1820s. Quarterly Journal History of Photography, v. I7, n. 3, p. 284-295, 1993. Disponível em: <http:// www.midley.co.uk/>.Acesso em: 19 maio 201 I. 